129

Received: October 20, 2016

Accepted: November 9, 2016
Journal of Electrical Engineering and Information Technologies, Vol. 1, No. 1-2, pp. 75-81 (2016)

In print: ISSN 2545-4250

On line: ISSN 2545-4269

UDC: 004.738.5:339]:004.4/.6.032.6

Original scientific paper

\title{
BILLING SYSTEM FOR OTT SERVICES
}

\author{
Marko Porjazoski, Pero Latkoski, Borislav Popovski \\ Faculty of Electrical Engineering and Information Technologies, \\ "Ss. Cyril and Methodius" University in Skopje, \\ Rugjer Bošković bb, P.O. box 574, 1001 Skopje, Republic of Macedonia \\ \{markop, pero, borop\}@feit.ukim.edu.mk
}

\begin{abstract}
A b s t r a c t: In this paper we propose a functional architecture of billing system for Over the Top services. Since OTT services are very diverse provided over different access technologies, on different user devices, legacy billing systems designed for support of unique services in closed provider networks are no longer suitable for new OTT environment. So we propose more flexible approach in building billing systems.
\end{abstract}

Key words: billing system; OTT services; video streaming

\section{СИСТЕМ НА НАПЛАТА ЗА ОТТ СЕРВИСИ}

\begin{abstract}
А п с т р а к т: Во овој труд е предложена функционална архитектура на систем за наплата (билинг систем) за ОТТ (Over the Top) сервиси. Бидејќи ОТТ-сервисите се обезбедуваат преку различни пристапни технологии, различни кориснички уреди, постојните системи преку кои се врши наплатата се дизајнирани за поддршка на само поединечни сервиси во блиските провајдерски мрежи, па не се соодветни за новата ОТT околина. Во решението е предложен пофлексибилен пристап во развојот на системите за наплата.
\end{abstract}

Клучни зборови: систем за наплата; ОТТ сервиси; поток на видеоподатоци

\section{INTRODUCTION}

Over-the-top (OTT) refers to delivery of video, audio and other media over the Internet without having Internet service provider involved in the control or distribution of the content [1]. Content is transited over the ISP network and he may be aware of the contents of the Internet Protocol packets but it is not responsible for, nor able to control, the viewing abilities, copyrights, and/or other redistribution of the content. One example of system architecture for provisioning of OTT services is presented in Fig 1.

Furthermore, OTT services are meant to be device independent. It means that user should obtain same service on any device like smart phone, smart TV, laptop, set-top box, PC, etc.

One of the major backend functionalities of OTT system certainly are charging and billing. It should provide great flexibility to the service provider in the way how it will offer and charge different services to the end user.

The simplest form of charging the user is to ask him to pay prior for the certain service that he wants to subscribe too The second form of charging is prepaid concept where user has certain credit on his account and he spends it whenever he subscribe to some OTT service. These two solutions are suitable for users who do not want or are unable to sign a contract with the service provider [2,3].

Third possible solution for charging of OTT services is postpaid solution, where user signs contract with service provider and receives a bill once a month for delivered services.

Prepaid and postpaid billing system is easy to implement in closed network where network provider is also a service provider. Having in 
mind the diverse of possible OTT services, as well as diverse of possible access technologies and end user devices, it is obvious that legacy billing systems based on Call Data Record (CDR) and Usage Data Records (UDR) are not suitable for new OTT environment. So we need a new more flexible approach in building billing systems [4]. In paper [5] authors have stated that billing systems has to be more flexible in order to meet demands of new services. In [6], architecture to realize a flexible charging system is proposed for $3 \mathrm{G}$ networks, but this solution only supports legacy voice and data services.

In this paper we propose a functional architecture of billing system for OTT services which is already implemented and running within the OTT solution of one service provider in R. Macedonia.

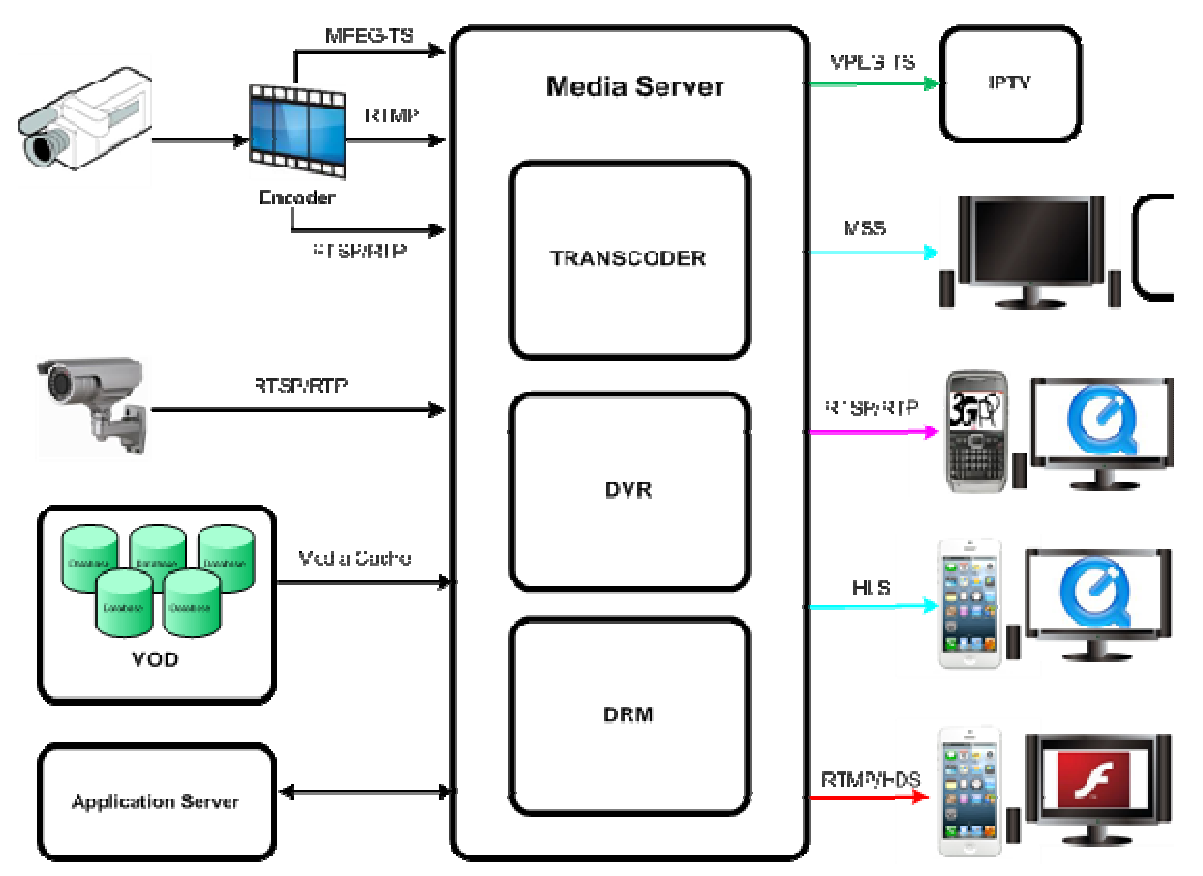

Fig. 1. System architecture for OTT services [1]

\section{DEFINITIONS OF TERMS}

Before explaining proposed billing system architecture, we will define some terms used in this paper and objects that are managed with this system.

OTT reseller is a partner that will use OTT service provider infrastructure to sale/resell OTT services to their customers are defined as OTT resellers. Proposed OTT solution enables creation of reseller specific content that will be available only to their customers.

User is an individual or company that registers at OTT service provider or its resellers billing system. One user can have multiple accounts.

Each account has its one credentials, i.e. username and password. Accounts are entities that are actually subscribed to some service. Single account can be used to get services on multiple devices. Two types of accounts are provided: prepaid or postpaid. User can have multiple accounts of different type.

Service plan is a set of OTT services that are offered to customers as a whole. Services belonging to one service plan do not need to be homogeneous, i.e. services in one service plan can be of different type.

Offer is a set of conditions under which service plane is offered to a customer like duration of subscription, payment type, price, promotional discounts etc.

Service is a basic unit provided to end users. Some examples of different services are: streaming of live TV or radio program, streaming of video or audio content on demand, available min- 
utes for content recording, or available number of devices aloud per account etc.

\section{Functional architecture of billing system for OTT services}

Proposed functional architecture of billing system for OTT services is presented in Fig. 2, and it consist of several functional blocks:

- Partners/resellers management functional block is responsible for definition and control of partner companies access and service definition rights. This will allow partner companies to resell services provided by service provider, owner of this system, or to use service provider infrastructure to provide their own services to their customers.

- Users and accounts management functional block is responsible for user registration and management of accounts and their credentials. As an option this functional block may allow creation of temporary users and accounts meant for testing of OTT services before customers makes their final decision to subscribe.

- Service management is a functional block that should provide functionalities for service definition, service provisioning, creation of service plans and service plan's offers. Depending on his rights, reseller can have access to these functionalities in orders to define their own services and services plans for their customers.
- Subscription management functionalities should allow flexible assignment of subscriptions of different service plans to prepaid and postpaid accounts.

- Billing engine is meant to calculate total subscription cost for postpaid accounts and to generate invoices.

- Credit control should check prepaid accounts credit each time before user is subscribed to new service plan in order to verify whether there are sufficient funds to cover the cost of subscription.

- Payment processing functional block should check timely payment of invoices and provide functionalities to enable alternative methods for payment of invoice such as m-banking or e-banking.

- Report generation should enable creation of different kind reports related to all aspect of OTT billing system. For an example timely reports on user subscriptions or reports for outstanding invoices, etc.

- Notification engine should enable sending notifications to users about some promotions, about expiration date of its subscription, notification about credit left to prepaid account, etc.

- OTT mediation is a functional block that will provide communication interfaces and APIs for integration of OTT billing system with other entities involved in OTT services delivery like OTT headed, DRM systems, server for control of partners/resellers licenses, etc.

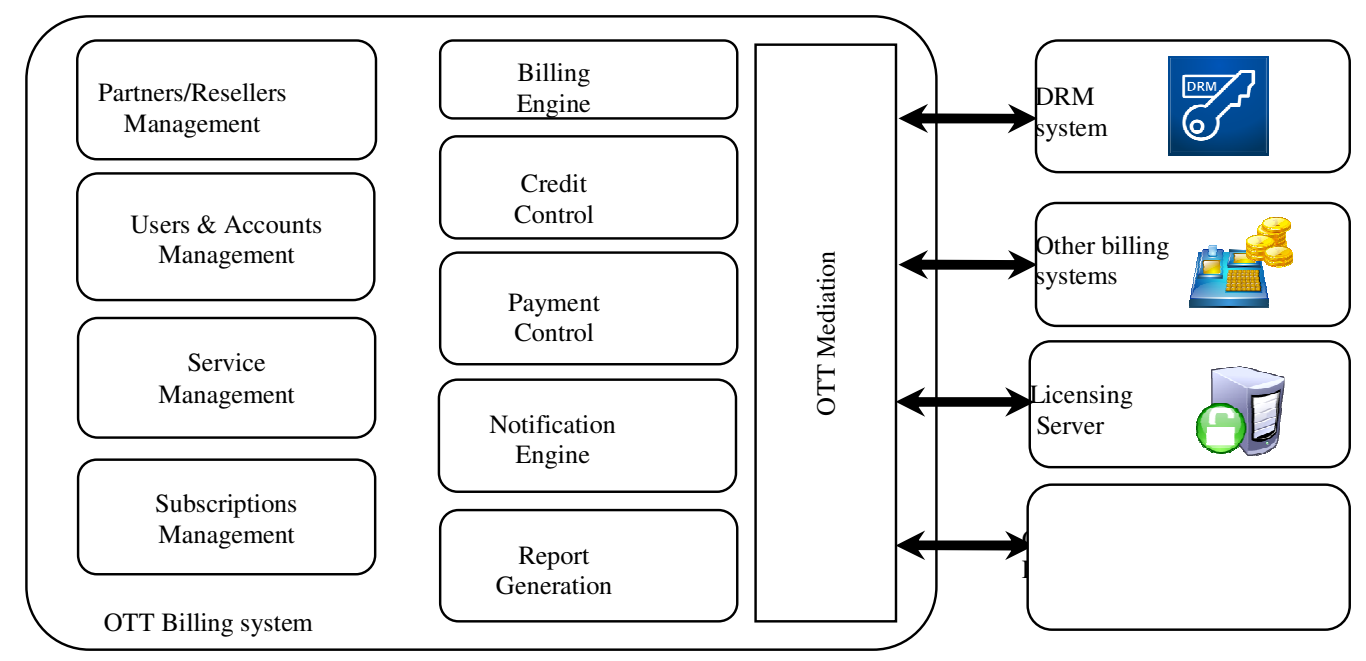

Fig. 2. Functional architecture of billing system for OTT services 


\section{SOFTWARE IMPLEMENTATION OF BILLING SYSTEM FOR OTT SERVICE PROVIDERS}

All the functionalities of the proposed billing solution can be implemented in software. Components of the software implementation of billing system for OTT services are presented in Figure 3.

Main part of this implementation are databases where all the records about resellers, users, accounts, services, service plans, offers etc. are stored.

Administrative Graphical User Interface (GUI) is a modular solution providing access to different databases and records depending on administrative privileges of the logged user. In order to provide access to administrative stuff any ware at any time we recommend administrative GUI to by web based, i.e. it can be access over secured HTTP(S). For that reason HTTP server has to be engaged. Databases can be hosted on single or multiple machines or in the cloud depending on provider's infrastructure and number of expected customers and subscriptions.

OTT mediation software should provide communication interfaces and APIs with other entities involved in OTT services provisioning. It consists of several modules also, each responsible to respond to particular request sent by peering entity.

OTT mediation Billing Module is responsible for communication between OTT billing sys- tem with OTT headend and other billing systems. OTT mediation will push some information to OTT headend necessary for the proper functioning of the system, like services definition for example, or it will respond to paired systems requests.

Upon incoming request Billing Module will share subscription information of users registered in OTT billing system.

Notification module should generate notifycation about user subscriptions, for example subscription expiration date, or credit limit, or some promotions, and send them to users through OTT headend.

DRM module should communicate with the third party DRM management system to implement appropriate security mechanisms for content protected by DRM.

Licensing module is meant to communicate with licensing server in order to find out details about partner/reseller's access rights and privileges.

Depending on the incoming request OTT mediation should construct its response based on the information that he found in the OTT billing databases.

We recommend usage of secured $\operatorname{HTTP}(\mathrm{S})$ for communication between OTT mediation and other OTT system entities with json (Java Script Object Notation) formatting of request and response messages sent or received, form or to OTT mediation.

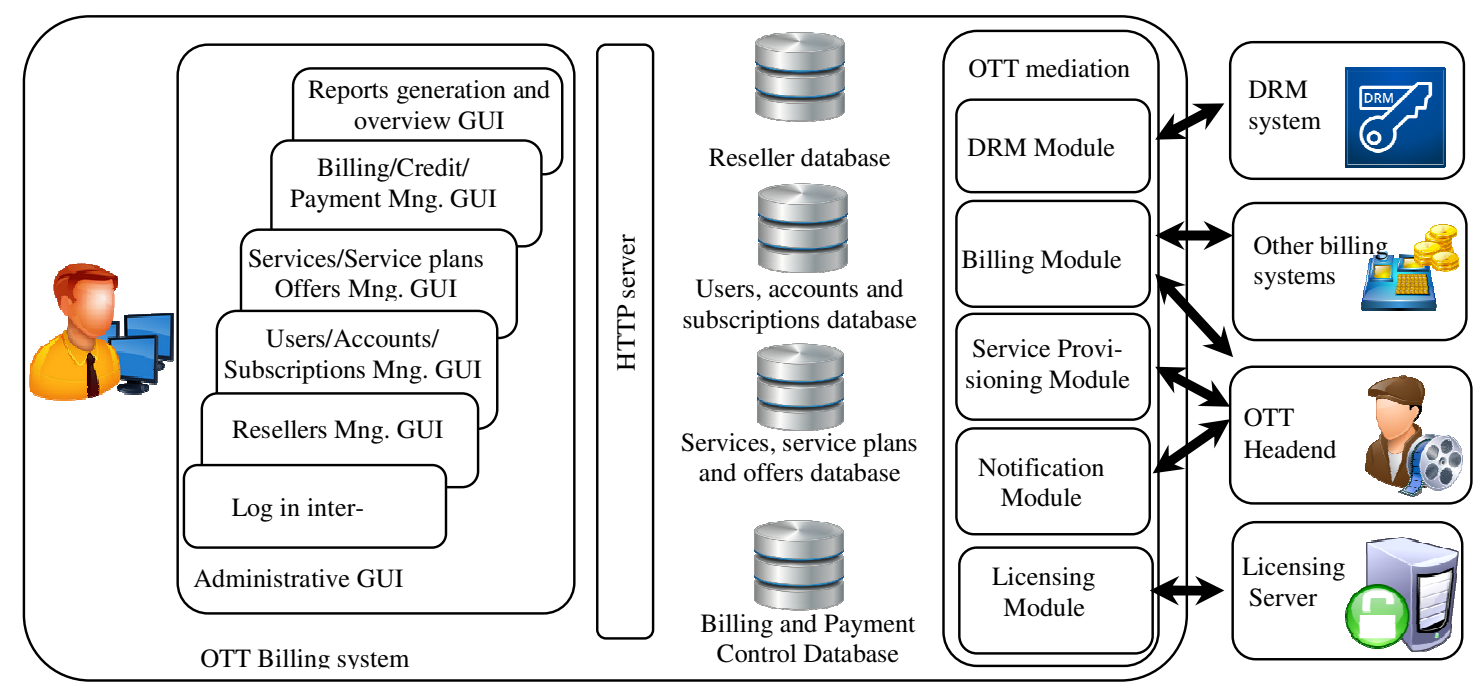

Fig. 3. Software implementation of billing system for OTT services 
Some example request and response messages sent or received by OTT mediation in order to get data from billing system are:

- Get(BillingData) - request sent by OTT head end in order to find out service plans that user is subscribed to and which services should be provided. OTT mediation billing module should respond with response (BillingData) message containing information about user data subscriptions.

- Get(ServicePlans) - request sent by OTT headend to find out a set of services included in each service plan. OTT mediation billing module should send response (ServicePlans) with service plans content defined in OTT billing system.

- Post(Notification) - request sent by OTT mediation notification module to OTT headend containing notification message that should be delivered to users. OTT mediation notification module should expect response on the outcome of notification delivery.

- Get(LicenseInfo) request sent by OTT mediation licensing module in order to find out reseller's access rights and privileges.

Since OTT billing system will use DRM system services, mediation software should adopt messaging format provided by the third party DRM solution. Usually messaging format used for this purposes are based on SOAP (Simple Object Access Protocol) and WSDL (Web Services Description Language) [7].

\section{SERVICES, SERVICE PLANS AND OFFERS DEFINITION AND PROVISIONING}

Parameters required for service definition are following:

- ResellerID - unique reseller identifier, that will be used to associate service to appropriate reseller;

- ServiceType - some of the supported service types like TV channel, radio channel, number of recording minutes etc.;

- ServiceName - name of defined service;

- ServiceURL - Unified resource location where service can be reached;

- SupportedBitrates - in case of streaming service type this parameter defines list of available bitrates for different streaming quality.
After definition service info is stored in local database and then sent to OTT headend by request trough communication interface between OTT mediation and OTT headend. Service data is sent to OTT headend in json format presented in Figure. 4.

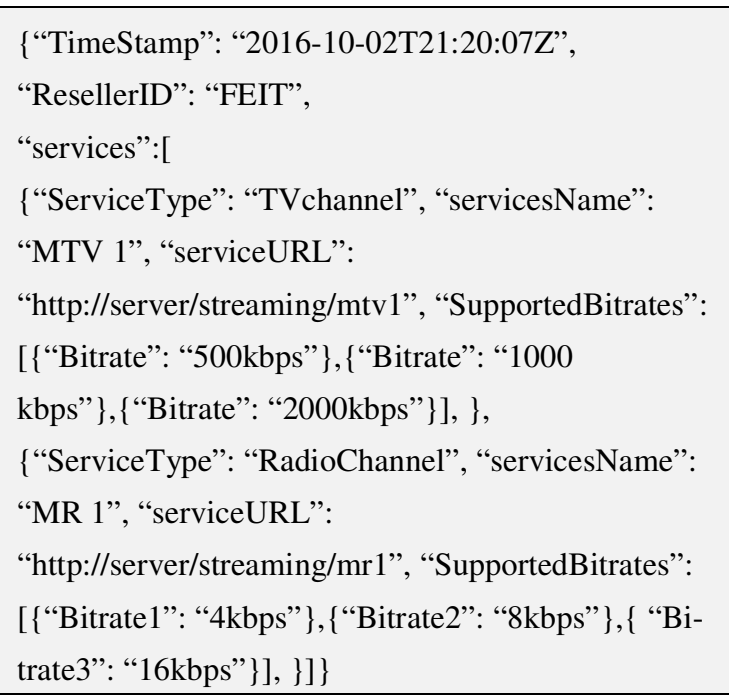

Fig. 4. Service data in json format.

In Figure 4 definition for two services is presented. The first service is a TV channel named as MTV1, which streaming URL is "http://server/ streaming/mtv1" and it has three different streaming bitrates 500, 1000 and $2000 \mathrm{kbps}$. The second service is a streaming service for radio channel MR1. "http://server/streaming/mrl" is a URL to reach this streaming service and it has also three supported streaming bitrates 4,8 and 16 kbps.

Service plan is a set of services offered to users as a whole. The conditions under which customers subscribe to service plan are defined in service plan offers. Parameters defining offers are following:

- ResellerID - unique reseller identifier;

- ServicePlanName - name of service plan which offer is defined;

- OfferName - name of the offer;

- ValidityPeriod - Time period in days for how long offer is valid;

- Price-Offer price;

- Discount - price discount in some promotional period;

- PromotionPeriod - Duration of promotional period in days. 
After defining service plans and their offers in OTT billing, they are forwarded to OTT headend using messages structured in json format as shown in Figure 5:

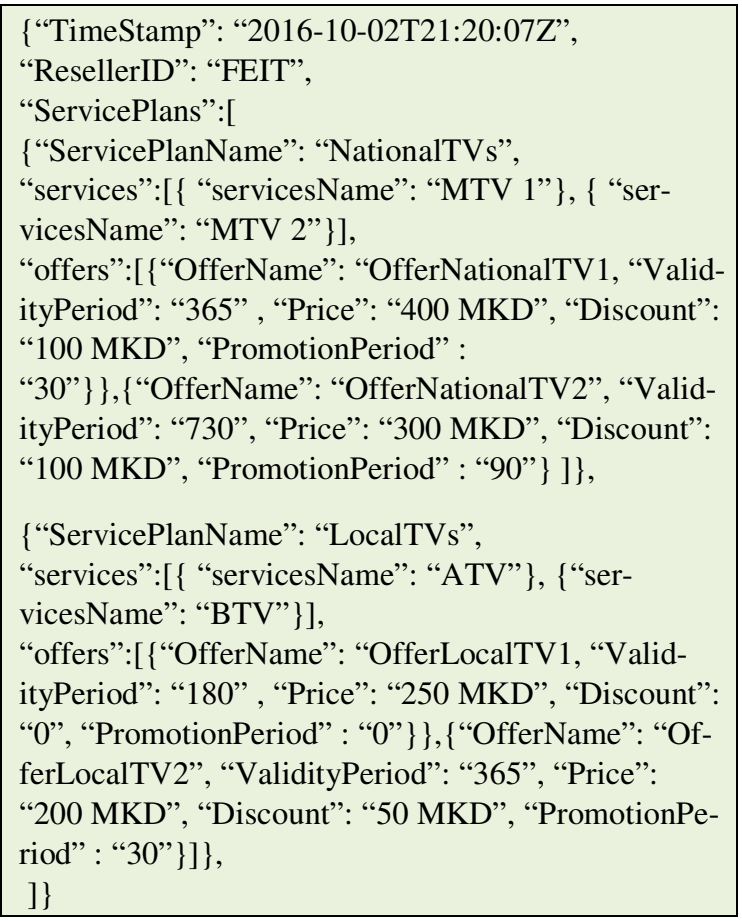

Fig. 5. Service plan's and their offers data in json format.

Data presented in Figure 5 defines two service plans, each with two different offers. Fires service plan names as "NationalTVs" consists of two services: MTV1 and MTV2. This service plan has two offers named as "OfferNationalTV1" and "OfferNationalTV2". The first offer nave validity period of 355 days, its monthly price is $300 \mathrm{MKD}$, promotion period is 30 days and discount for this period is $100 \mathrm{MKD}$. The second offer for service plan "NationalTVs" is named as "OfferNationalTV2". It has validity period of 730 days, monthly price of $300 \mathrm{MKD}$, promotion period of 90 days with monthly discount of 100 MKD. The second service plan defined with json structure in Figure 5 is named as "LocalTVs". It has also two offers named as "OfferLocalTV1" and "OfferLocalTV2". The first one have validity period of 180 days while the second have validity period of 365 days. Price for the first offer is 250 MKD with no promotion and discount, while validity period for the second offer is 365 days with monthly price of 200 MKD and discount of 50 MKD within 30 days promotion period.

\section{USERS, SUBSCRIPTIONS AND LICENSING}

One way to protect OTT system from illegal and unauthorized use is implementation of so called licensing server. Licensing server holds the records about number of users and number of subscriptions allowed for some reseller. During the process of user creation and subscription assignment, OTT billing checks the reseller's license status at licensing server to ensure that there is a free license that can be assigned to new user and user's subscription. If there is no free license for particular reseller, creation of new user and its subscriptions will be discarded.

Upon successful user creation and subscription assignment, data are saved to local database. In order to enable automatic and instant service provisioning, user data is sent to OTT headend to allow user access to particular service.

A format of message with user data sent to OTT headend is presented in Figure 6.

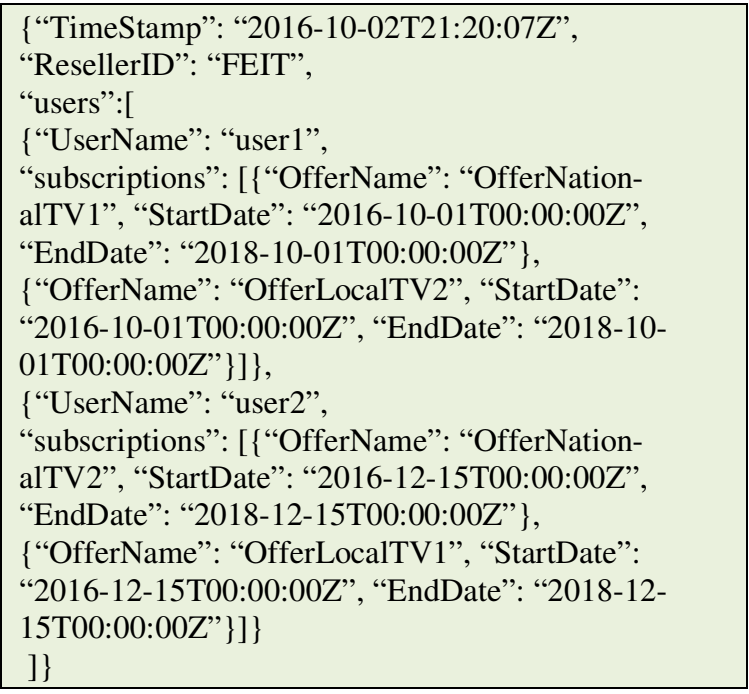

Fig. 6. User subscriptions data in json format.

Data presented in Figure 6 are subscription information for two different users identified by their user names: "user1" and "user2". User1 is subscribed to "OfferNationalTV1" and "OfferLocalTV2", offers defined for service plans "NationalTVs" and "LocalTVs" respectively. User2 is subscribed to "OfferNationalTV2" and "OfferLocalTV1". Subscription period is defined with "StartData" and "EndDate" values. OTT headend should provide user access to services included in each service plan that he is subscribed to within 
subscription period. Outside of this period access to services should be blocked for that particular user.

\section{CONCLUSIONS}

Considering the fact that the existing billing systems are not flexible enough to be engaged in provisioning of OTT services, it is clear that we need a new billing system that will meet the requirements. In this paper we have proposed a flexible modular architecture of OTT billing system that should meet current and future requirements of OTT services.

Proposed OTT billing architecture can be easily implemented by using standard programming languages (php, ASP.NET, or Java), well established database systems (mySQL, ORACLE, or Microsoft SQL) and HTTP servers (IIS, Apache etc).

This solution can be easily integrated with other billing and DRM systems through appropriate communication and AP interfaces.

\section{REFERENCES}

[1] Wowza Media Systems, https://www.wowza.com/.

[2] Robert Törnkvist, Ralph Schubert: Ericsson convergent charging and billing, https://www.ericsson.com/ericsso n/corpinfo/publications/review/2009_01/files/Charging. pdf.

[3] Ericson White Paper: Prepaid postpaid convergent charging, http://www.idc-online.com/technical_references/pdfs/data_communications/PREPAID_POSTPAID_ CONVERGENT.pdf

[4] Xie Qingrui: Reshape your billing support system Huawei, Huawei Technologies, APR 2008, Issue 40, pp 43-46, http://www1.huawei.com/en/static/HW- 079821.pdf.

[5] Cliff Lui, Hui Ka Yu, Richard Shi, Jacky Pang: Telecommunications Billing in the Competitive Wireline Arena, May 2007, http://www.viperfusion.com/ wordpress/wpcontent/uploads/2007/11/2007PaperTelecommu nicationsBillingandStrategy.pdf

[6] R. Kühne, U. Reimer, M. Schläger, F. Dressler, C. Fan, A. Fessi, A. Klenk, G. Carle: Architecture for a ServiceOriented and Convergent Charging in $3 G$ Mobile Networks and Beyond, 2005, https://www.net.in. tum.de/fileadmin/bibtex/publications/papers/kuehne05ar chitecture.pdf

[7] Verimatrix, http://www.verimatrix.com/ 
